\title{
La objeción presidencial a actos legislativos en Colombia
}

\section{Presidential Objection to Legislative Acts in Colombia}

https://doi.org/10.15332/iust.v0i17.2422

\section{José Darío Argüello Rueda}

Abogado, magister en Análisis Politico, doctorando en Politicas Públicas. Miembro de las Asociaciones Colombianas de Derecho Procesal Constitucional, Argentina de Justicia Constitucional y Mundial de Justicia Constitucional. Profesor de Derecho Constitucional e investigador de la Corporación Universitaria del Caribe CECAR. Correo electrónico: jose.arguellor@cecar.edu.co

\section{Resumen}

En el 2012, luego de que el presidente de turno Juan Manuel Santos Calderón objetara el Acto Legislativo de Reforma a la Justicia, se abrió uno de los debates constitucionales más importantes del momento, el cual fue conocido por los altos tribunales como los son la Corte Constitucional y el Consejo de Estado. En el presente artículo se hace un análisis histórico de la competencia de objeción a reformas constitucionales, se observa en un ejercicio de análisis de referentes las disposiciones constitucionales de algunos países de América Latina sobre dicha atribución, se desarrolla una carga argumentativa de las razones de improcedencia, además de examinar sentencias de los tribunales antes mencionados en lo que respecta al tema de investigación.

Palabras clave: Objeción presidencial, actos legislativos, competencia, constitución, improcedencia.

\begin{abstract}
In 2012, after the President of the day objected to the Legislative Act of Reform of Justice, one of the most important constitutional debates of the moment was opened, which was known by the high court's such as the Constitutional Court and the Council. of State. In the present article, a historical analysis of the competence of objection to constitutional reforms is made, it is observed in an exercise of analysis of referents the constitutional dispositions of some Latin American countries on said attribution, an argumentative load of the reasons of inadmissibility, in addition to examining judgments of the aforementioned Courts with regard to the subject of investigation.
\end{abstract}

Keywords: Presidential Objection, legislative acts, competence, constitution, unlawful. 


\section{Résumé}

En 2012, après que l'actuel président Juan Manuel Santos Calderón s'est opposé à l'acte législatif de réforme de la justice, l'un des débats constitutionnels les plus importants du moment a été ouvert, connu des hautes cours telles que la Cour. Constitutionnel et le Conseil d'État. Dans cet article, une analyse historique est faite de la compétence pour s'opposer aux réformes constitutionnelles, on l'observe dans un exercice d'analyse concernant les dispositions constitutionnelles de certains pays d'Amérique latine sur ladite attribution, un fardeau argumentatif des raisons de Irrecevabilité, outre l'examen des jugements des juridictions précitées concernant l'objet de l'enquête.

Mots-clés: objection présidentielle, actes législatifs, compétence, constitution, irrecevabilité. 


\section{La objeción presidencial a actos legislativos en Colombia}

José Dario Argüello Rueda

\section{INTRODUCCIÓN}

Luego que el presidente de la república, para el período 2010 - 2014, Juan Manuel Santos Calderón, objetara el Acto Legislativo No. 07 de 2012 "por medio del cual se reforman artículos de la Constitución Política con relación a la Administración de Justicia y se dictan otras disposiciones" se inició un debate sobre la procedencia o improcedencia de dicha competencia presidencial de objeción a reformas constitucionales, la cual, siendo netamente constitucional, llega a trascender al ámbito político. Las razones en las que se fundó el ejecutivo al hacer la objeción, fue la inconstitucionalidad e inconveniencia nacional de dicho acto legislativo (Argüello-Rueda, 2014), acusado de contener gran cantidad de irregularidades que atentarían contra el ordenamiento jurídico colombiano y la estabilidad del Estado. Sin embargo, el hecho de la objeción a esta reforma constitucional plantea un escenario de vulneración de principios y normas constitucionales y una extralimitación de funciones y auto adjudicación de competencias por parte del jefe del ejecutivo.

El artículo inicia explicando las diferencias entre el poder constituyente y poder de reforma a la constitución, para luego partir del análisis histórico de las objeciones presidenciales a actos legislativos, permite visualizar antecedentes y desarrollos normativos que en su momento regulaban dicha competencia del ejecutivo, y así, pasar a establecer las razones de improcedencia de tal atribución, desde la sentencia del Consejo de Estado del 16 de septiembre de 2014, en la que se declara la nulidad del Decreto 1351 de 2012 y algunas sentencias de la Corte Constitucional y de la misma Constitución Política de Colombia, apoyando dicho análisis, en un ejercicio de estudios de referentes con países de América Latina, permite conocer si esta competencia del ejecutivo se contempla en sus constituciones o qué posición tiene el marco constitucional de dichos Estados frente a la posibilidad de objetar reformas constitucionales.

\section{EL PODER CONSTITUYENTE Y EL PODER DE REFORMA A LA CONSTITUCIÓN}

Antes de hablar de reformas constitucionales y de objeciones por parte del ejecutivo a estas, con el fin de generar mayor comprensión en cuanto a los roles y competencias dentro de la organización del Estado, debe entenderse, a la luz del 
constitucionalismo moderno, que el titular del poder político dentro de un Estado es el pueblo (Böckenförde y de Agapito, 2000), esto debido a que es el titular de la soberanía, y en consecuencia, del poder constituyente (Kalyvas, 2005), para que así pueda darse su Constitución, y organizar su Estado de la manera que lo considere conveniente. Este poder es creador de derecho, ya que de él emana todo el ordenamiento jurídico y no existe poder superior (Roig, 1997), ni siquiera la misma Constitución, toda vez que el poder constituyente no se encuentra sujeto a normativas anteriores, ni emana de ellas. Así lo establece el Consejo de Estado en la sentencia objeto de análisis.

El Poder Constituyente es un poder revolucionario ya que su función no es conservar el orden sino modificarlo radicalmente, en esto se diferencia del defensor de la Constitución, cuya función es conservarlo; el Poder Constituyente tiene una función revolucionaria, en cambio, el guardián de la Constitución tiene una función conservadora (Sentencia 110010324000201200220, 2014).

En distinto modo, el poder de reforma de la Constitución es un poder derivado (Valle, 1993), establecido, regulado y limitado por la misma Constitución, su competencia es modificarla mediante procedimientos especiales establecidos en ella dentro de sus propios términos (Nogueira, 2009). Con estos límites se busca evitar que el poder constituido mediante las reformas parciales, que está facultado para realizar, lleve a cabo cambios radicales en los postulados constitucionales (GarcíaJaramillo, 2016), ya sea organización política, institucional, social, económica o demás, alterando la esencia del texto constitucional, sus principios fundantes $\mathrm{y}$, por ende, la concepción de Estado.

\section{LA OBJECIÓN PRESIDENCIAL A ACTOS LEGISLATIVOS EN LA HISTORIA CONSTITUCIONAL COLOMBIANA}

La Constitución Política de Colombia establece tres mecanismos de reforma constitucional, uno realizado de manera directa por el Congreso de la República, por una Asamblea Constituyente o por referendo, estos dos últimos donde el pueblo tiene mayor participación, sea a través de los representantes en la Asamblea Constituyente, o participando con su voto en el referendo reformatorio de la Constitución. Respecto del acto legislativo como acto de reforma constitucional, el artículo 375 de la Carta Política establece que:

Podrán presentar proyectos de acto legislativo el Gobierno, diez miembros del Congreso, el veinte por ciento de los concejales o de los diputados y los ciudadanos en un número equivalente, al menos, al cinco por ciento del censo electoral vigente. El trámite del proyecto tendrá lugar en dos períodos ordinarios y consecutivos. Aprobado en el primero de ellos por la mayoría de los asistentes, el proyecto será publicado por el Gobierno. En el segundo período la aprobación requerirá el voto de la mayoría de los miembros de cada Cámara. En este segundo período sólo podrán debatirse iniciativas presentadas en el primero (Constitución Política de Colombia, Art. 375). 
La lectura del presente artículo permite afirmar que, dentro del procedimiento de trámite del Acto Legislativo no se contempla la sanción presidencial, menos aún, la facultad de objeción, lo que abre el polémico debate, al no encontrarse taxativamente regulado.

En cuanto a la atribución de objetar actos legislativos, el primer antecedente histórico se encuentra en la Constitución Granadina de 1843, la cual mediante su artículo 73 le otorgaba la competencia al ejecutivo de objetar este tipo de reformas constitucionales al establecer que:

Ningún proyecto de ley o de otro acto legislativo, aunque aprobado por ambas Cámaras, tendrá fuerza de ley sin la sanción del Poder Ejecutivo. Si éste hallare por conveniente dársela, lo hará mandándolo ejecutar y publicar; pero si hallare por conveniente rehusársela, lo objetará y devolverá a la Cámara de su origen con las objeciones que le haga (Constitucion Granadina de 1843, Art. 73).

Ya en la Constitución de 1886, pese a que en su artículo 209, mediante el cual se establece el mecanismo de reforma de acto legislativo y su procedimiento, no deja claro si el presidente tiene la facultad de objetar dicha reforma; el artículo 151 numeral 4 consagraba "Decidir definitivamente sobre la exequibilidad de actos legislativos que hayan sido objetados por el Gobierno como inconstitucionales" (Constitución Política de Colombia de 1886, Art. 151, \# 4) donde se sobreentiende que si la Corte Suprema de Justicia tenía la facultad de declarar la exequibilidad de los actos legislativos que hubiesen sido objetados por el Gobierno, es porque este, en cabeza del presidente de la república, contaba con dicha competencia.

Otro antecedente muy importante, y el único que va más allá de ser un enunciado constitucional, sino que fue llevado a la práctica, fue la Objeción Presidencial al Acto Legislativo No. 3 de 1910, por el presidente de turno Carlos Restrepo, quien expreso "No está dispuesto expresamente en nuestras disposiciones legales que esta clase de actos quede sujeta a las objeciones del poder ejecutivo; pero la 'jurisprudencia' de nuestro derecho constitucional permite que se le hagan observaciones" frente a lo que la Asamblea Nacional ${ }^{1}$ decidió (como lo manifiesta el Consejo de Estado):

No entrar a examinar las observaciones del poder ejecutivo porque considera que ni la Constitución, ni los actos reformatorios de la misma, ni las leyes, lo facultan para hacer observaciones a los proyectos de reformas constitucionales. En consecuencia, decide devolverle el proyecto para los fines legales ulteriores (Sentencia 110010324000201200220, 2014).

Con lo anterior, se puede afirmar que la competencia de la objeción a actos legislativos por parte del ejecutivo es indiferente y contraria al constitucionalismo colombiano, ya que solo dos textos constitucionales llegaron a permitirla, y solo se

$1 \quad$ La Asamblea Nacional cumplía funciones legales y constitucionales. Por cinco años (1905 - 1910) fue la encargada de las reformas constitucionales. 
llevó a la práctica en una ocasión, cuyo intento fue fallido, como forma de garantizar un verdadero orden constitucional y salvaguardar la integridad de la Carta Política de la época.

\section{ANÁLISIS DE REFERENTES: LA OBJECIÓN PRESIDENCIAL EN LAS CONSTITUCIONES DE ALGUNOS PAÍSES DE AMÉRICA LATINA}

Al hacer un análisis de referentes con varias de las constituciones de América Latina, se observa que la tendencia es la improcedencia de la Objeción presidencial a actos legislativos y demás reformas constitucionales; sin embargo, el único país latinoamericano que contempla en su texto constitucional la facultad presidencial de objeción a este tipo de reformas constitucionales, es Chile, donde se permite el rechazo total u observaciones parciales por parte del ejecutivo, así lo consagra el artículo 128 de la Constitución de dicho país.

En el caso de Ecuador, pese a que en la actualidad, con la entrada en vigencia de la reciente Constitución de 2008, no se incluye al presidente de la república en los procedimientos de aprobación y publicación de los actos legislativos, negando así la posibilidad de objeción de los mismos; en el pasado, la Constitución de 1998 en su artículo 280 establecía como requisito de dicha reforma constitucional la sanción presidencial y, por ende, le otorgaba competencia a este de objetar dichas reformas.

Contrario a las dos constituciones antes señaladas, en el caso de Perú, su texto constitucional explícitamente en su artículo 206 prohíbe la objeción o veto presidencial a los actos legislativos cuando establece que "(...) La ley de reforma constitucional no puede ser observada por el presidente de la república" (Constitución Política de Perú, Art. 206).

Igualmente, en la República de Venezuela, al tenor literal de su artículo 175 se establece que "El presidente de la república no podrá objetar las enmiendas o reformas y estará obligado a promulgarlas dentro de los diez días siguientes a su sanción. Si así no lo hiciere se aplicará lo previsto en el artículo 175" (Constitución de la República de Venezuela, Art. 175). En esta misma línea, La Constitución Política de la República de Nicaragua, prohíbe el veto presidencial a actos reformatorios de la Constitución, y solo le otorga competencia a este para trámites de publicación, al igual que la Constitución Política de la República Dominicana que establece que ningún poder o autoridad, inclusive las aclamaciones populares, se puede oponer a las reformas constitucionales y hace igualmente expresa la prohibición de observación por parte del ejecutivo.

En este mismo sentido, en la Constitución Política de la República de Panamá, se limitan las funciones del presidente a la publicación del acto legislativo y no se le permite participar del proceso de aprobación con competencias como la objeción presidencial, así lo establece el artículo 313 numeral 1 “(...) el cual debe ser publicado 
en la Gaceta Oficial y transmitido por el Órgano Ejecutivo a dicha Asamblea (...)” y el artículo 314

El Acto Constitucional aprobado con arreglo a cualquiera de los procedimientos señalados en este artículo y en el artículo anterior, empezará a regir desde su publicación en la Gaceta Oficial, la cual deberá hacerse por el Órgano Ejecutivo, dentro de los diez días hábiles que siguen a su ratificación por la Asamblea Nacional (...) (Constitución Política de la República de Panamá, Arts. 313, 314).

Siguiendo esta línea, en la Constitución de la República de Bolivia se encuentra explícita la prohibición al ejecutivo para objetar o vetar una reforma constitucional, como lo establece su artículo 230 numeral 3 "La ley declaratoria de la reforma será enviada al ejecutivo para su promulgación, sin que este pueda vetarla".

Como último referente, está el caso de Costa Rica, en este país se requiere para la aprobación de la reforma constitucional del voto a favor de las dos terceras partes de la totalidad de los miembros de la Asamblea, acto seguido, se comunica al ejecutivo para su publicación y observancia. Lo anterior lo establece dicha Constitución en su artículo 195 numeral 7, así

La Asamblea Legislativa, en sus primeras sesiones, discutirá el proyecto en tres debates, y si lo aprobare por votación no menor de dos tercios de votos del total de los miembros de la Asamblea, formará parte de la Constitución y se comunicará al Poder ejecutivo para su publicación y observancia (Constitución Política de la República de Costa Rica, Art. 195).

En este caso, la palabra "observancia" puede permitir diversas interpretaciones y llegarse a pensar en una posible facultad presidencial de objetar, pero al analizar que esta antecedida por el término "comunicara" se cierra dicha posibilidad, ya que debe entenderse que, si la reforma se comunica, es porque ya está decidida, no tiene posibilidad de devolución ni de cambio, por tanto, el presidente se debe limitar a su publicación y acatamiento.

\section{EL DECRETO 1351 DE 2012: PROCESO DE NULIDAD POR INCONSTITUCIONALIDAD ANTE EL CONSEJO DE ESTADO}

Si ya era polémico el Acto Legislativo que reformaba artículos de la Constitución en cuanto a la administración de justicia, sumado a esto, la objeción por parte del presidente de la república a dicha reforma constitucional, no es menos cuestionable, es decir, el Decreto 1351 de 2012, por medio del cual el presidente convoca al Congreso de la República a sesiones extraordinarias para que se ocupara de examinar las objeciones por él realizadas al Acto Legislativo 007/11 Senado -143/11 Cámara, acumulado a los proyectos 09/11, 11/11, 12/11 Y 13/11 Senado, por medio del cual se reforman artículos de la Constitución Política con relación a la Administración de Justicia y se dictan otras disposiciones. 
En el decreto en cuestión, el presidente inicia su argumentación de procedencia de las objeciones, aduciendo el principio de colaboración armónica, acudiendo al artículo 113 de la Constitución que establece que “(...) Los diferentes órganos del Estado tienen funciones separadas pero colaboran armónicamente para la realización de sus fines" (Constitucion Política de Colombia, Art. 113), ya que según él, como jefe de Estado, está en la obligación de hacer respetar y cumplir la Constitución, y garantizar la efectividad de los principios en ella contenidos.

También argumenta, que en ninguna parte del articulado constitucional se le prohíbe la posibilidad de objetar actos legislativos, y que por el contrario, la Ley 5 de 1992 establece que "Las disposiciones contenidas en los capítulos anteriores referidas al proceso legislativo ordinario que no sean incompatibles con las regulaciones constitucionales, tendrán en el trámite legislativo constituyente plena aplicación y vigencia" (Ley 5 de 1992, Art. 227), disposiciones dentro de las que se encuentra la objeción a los proyectos de ley, lo cual según el presidente, no es contrario en su procedimiento a la Constitución, y con base en este artículo citado, se puede realizar frente a los actos legislativos.

Surge ahora otro punto de discusión, si es procedente que el presidente convoque al Congreso de la República a conocer de las objeciones a un acto legislativo, cuando la Constitución establece en su artículo 375, que el procedimiento de aprobación de este se debe realizar en dos períodos ordinarios consecutivos. Frente a lo que el presidente en dicho decreto establece "Que el trámite de objeciones es un procedimiento distinto del de aprobación del acto legislativo, respecto del cual no opera la limitación a que se refiere el artículo 375 constitucional" (Decreto 1351 de 2012).

Frente a este decreto, se interpone una Acción de Nulidad por Inconstitucionalidad $\mathrm{y}$, entre otros argumentos, la actora aduce que el presidente carece de competencia para objetar actos legislativos, ya que si bien es cierto que ninguna norma constitucional lo prohíbe, tampoco hay una que lo autorice, y en virtud del principio de legalidad, que se encuentra contemplado en los artículos 6 y 121 del texto superior "Ninguna autoridad del Estado podrá ejercer funciones distintas a las que le atribuyen en la Constitución y en la ley" (Constitución Política de Colombia, Art. 121). Igualmente argumenta, que a la luz del artículo 149 superior, las reuniones que realice el Congreso fuera de lo establecido por la Constitución no tienen validez, ya que el artículo 375 de la Carta Política, como se dijo anteriormente, establece que se desarrolle el trámite en dos períodos ordinarios consecutivos y, además, que no podía el Congreso archivar un acto legislativo que ya había cumplido con sus trámites de aprobación.

Frente a todo lo anterior, en la contestación, por parte del apoderado del Ministerio del Interior, se argumenta que de conformidad con los artículos 138, 165, 166 y 200 de la Constitución, el Gobierno es competente para convocar al Congreso de la República a sesiones extraordinarias, y que también lo es para objetar actos legislativos.

Argumenta también el Ministerio del Interior, que existe dicha competencia de objeción con base en el principio de colaboración armónica y como una forma de salvaguardar la constitución, en los siguientes términos: 


\begin{abstract}
El propósito de tales objeciones no fue otro que incluir 'un mecanismo de tipo preventivo, destinado a evitar posibles manipulaciones o graves alteraciones de la potestad de reforma', como 'manifestación del principio de colaboración armónica', atendiendo además al hecho, ya mencionado, de que 'los mecanismos ordinarios previstos en el ordenamiento para controlar la legitimidad del proceso de reforma constitucional no ofrecen una solución inmediata que evite la entrada en vigencia de actos legislativos en los que se hayan verificado graves afectaciones del orden constitucional' y en razón, también, de la 'necesidad de preservar la existencia de la Constitución Política y garantizar la vigencia plena de sus valores o principios, y la de los derechos y deberes en ella incorporados' (Sentencia 110010324000201200220, 2014).
\end{abstract}

También aparece como argumento en favor del Decreto 1351 de 2012, por parte de la Secretaría Jurídica de la Presidencia, que al momento en que la Corte Constitucional decidió declararse inhibida para pronunciarse de fondo sobre dicho Acto Legislativo por no haber sido promulgado, y en ese sentido no haber adquirido vigencia o nacido a la vida jurídica, que "el Tribunal constitucional validó la constitucionalidad del decreto, visto que si dicho decreto no hubiera producido efectos, el proyecto de acto legislativo no habría sucumbido" (Sentencia 110010324000201200220, 2014).

Ahora, otro cuestionamiento que surge es la competencia del Consejo de Estado para conocer y fallar la constitucionalidad de dicho decreto, frente a lo cual, el mismo Consejo de Estado en la Sentencia que emite en esta Acción de Nulidad por Inconstitucionalidad, en su acápite de consideraciones establece que solo se ocupará del Decreto demandado, y que no entrará a cuestionar la vigencia o no del acto legislativo. El artículo 237 de la Constitución Política de Colombia, en su numeral 2 establece como atribución del Consejo de Estado la de "Conocer de las acciones de nulidad por inconstitucionalidad de los decretos dictados por el Gobierno Nacional, cuya competencia no corresponda a la Corte Constitucional" (Constitucion Politica de Colombia, Art. 237, \# 2). Al analizar la naturaleza del Decreto 1351 de 2012, en aras de determinar si es competencia o no del Consejo de Estado conocer la constitucionalidad del mismo, se encuentra que este es un acto administrativo político o de gobierno, ya que tiene como fin convocar a otra rama del poder público, en este caso la legislativa, a cumplir con unas sesiones extras para examinarlo en el decreto estipulado, así las cosas, al tenor del artículo 104 de Ley 1437 de 2011, como lo establece en su numeral quinto "Los que se originen en actos políticos o de gobierno" la Jurisdicción de lo Contencioso Administrativo es la competente de conocer la acción de nulidad por inconstitucionalidad del decreto en cuestión.

\title{
4.1. Razones de improcedencia de la objeción presidencial a actos legislativos desde la Sentencia de Nulidad del Decreto 1351 de 2012
}

Dentro de la sentencia dictada por el Consejo de Estado, se encuentra el concepto emitido por el Ministerio Público, quien aparte de reconocer la competencia 
de esta jurisdicción para conocer de la presente acción de nulidad, realiza un ejercicio de argumentación de la improcedencia de las objeciones presidenciales a actos legislativos. Señala la entidad, que ninguna de las razones aducidas por el ejecutivo para sustentar la objeción realizada al acto legislativo de reforma a la justicia, encuentra admisibilidad en razones constitucionales y deja en claro que "las competencias y funciones públicas deben estar positivamente establecidas en la Constitución y en la Ley, por lo que ningún funcionario, órgano o institución pública puede hacer nada distinto a lo que allí expresamente se le faculta y ordena hacer" (Sentencia 110010324000201200220, 2014).

Establece también el ministerio público en su concepto, que el presidente de la república "no tiene ninguna competencia para cuestionar el hecho de que el mismo constituyente, en ejercicio de su poder soberano, haya establecido diferentes mecanismos para reformar la Carta Política" (Sentencia 110010324000201200220, 2014). Además, plantea el procurador que no se puede debido al principio de colaboración armónica de los poderes públicos, llegar a una invasión de funciones y competencias de las demás ramas, planteamiento que retoma el Consejo de Estado y desarrolla con base en el principio de separación de poderes. Resalta el Alto Tribunal, que este es uno de los principios fundantes de la Constitución Política de 1991, y por ende, del Estado colombiano, y recuerda una máxima contenida en el artículo 16 de la Declaración de los Derechos del Hombre y del Ciudadano de 1789 “Toda sociedad en la cual no esté establecida la garantía de los derechos, ni determinada la separación de los poderes, carece de Constitución" (Sentencia 110010324000201200220, 2014). Lo anterior, ya que la división de los poderes públicos, y el respeto de estos, permiten un ejercicio de poder limitado, al cual se le puedan hacer controles y evitar de esta forma la concentración de potestades y competencias que pudiese llegar a afectar las libertades de las personas frente al Estado. También la Corte Constitucional al respecto ha manifestado:

La separación de poderes es también un mecanismo esencial para evitar la arbitrariedad, mantener el ejercicio de la autoridad dentro de los límites permitidos por la Carta y asegurar así la libertad y seguridad de los asociados. La lógica de este dispositivo, no por conocida deja de ser esencial: la división de la función pública entre diferentes ramas permite que el poder no descanse únicamente en las manos de una sola persona o entidad, a fin de que los diversos órganos puedan controlarse recíprocamente (Sentencia C-251, 2002).

Establece también en su sentencia el Consejo de Estado, como razones de improcedencia de la objeción por parte del ejecutivo a los actos legislativos, el hecho de que sí se otorga esta competencia, implicaría hacer al presidente partícipe del poder constituyente derivado, no solo mediante la posibilidad de iniciativa de reforma, sino otorgándole protagonismo en la etapa de trámite y adopción de decisiones, lo que no fue la voluntad del constituyente primario en 1991, por otra parte, pese a que la Ley Quinta de 1992 establece la posibilidad de aplicar reglas propias del procedimiento legislativo ordinario, al de actos legislativos, no se encuentra dentro de estas la sanción 
presidencial, y por ende, tampoco la de objeción, como garantía de la voluntad, funciones y competencias del poder constituyente derivado, en representación del constituyente primario, como lo es el Congreso de la República, y resalta también el Tribunal, que esta posibilidad de objeción presidencial a reformas constitucionales:

\begin{abstract}
Desquicia los principios y valores fundantes del Constitucionalismo que logra su máxima expresión en el Estado de Derecho pues, por esa vía, se legitima el desbordamiento en el ejercicio de sus competencias constitucionales, y el desplazamiento del Poder Constituyente Derivado en manos del Ejecutivo, lo que indudablemente redunda en una concentración inusitada de poderes en su favor, que por lo demás, riñe con la filosofía que inspiró al Constituyente de 1991. Se violarían todos los principios fundantes y los pilares de la estructura constitucional del Estado, al desfigurarse el modelo del Estado colombiano instituido por la Asamblea Constituyente de 1991, que pretendió prevenir que una rama del poder público se convirtiera en suprema y que existiesen actos gubernamentales que escaparan al control judicial o al control político (Sentencia 110010324000201200220, 2014).
\end{abstract}

\title{
4.2. Improcedencia de las sesiones extraordinarias del Congreso de la República para examinar las objeciones presidenciales
}

El artículo 375 de la Constitución Política de Colombia deja claro que los trámites de aprobación de actos legislativos se deben surtir dentro de dos períodos ordinarios consecutivos, lo que implica, a contrario sensu, una prohibición de sesiones extraordinarias para conocer y examinar trámites relacionados con dicha reforma constitucional, "esto significa que cualquier acto de reforma a la Constitución Política que se tramite en más de dos períodos constitucionales, o pretermitiendo la exigencia de consecutividad o cuando se realiza en sesiones extraordinarias, carece completamente de validez" (Sentencia 110010324000201200220, 2014). Además, en concepto del 22 de junio de 2010, emitido por la Sala de Consulta y Servicio Civil señalo que:

Tales sesiones extraordinarias se circunscriben en cuanto a su duración y a las materias que pueden tratarse, a la respectiva convocatoria gubernamental, con la limitación que se deriva del artículo 375 de la Constitución, el cual establece que las reformas constitucionales deben ser tramitadas en "dos períodos ordinarios y consecutivos", por lo que, "como lo tiene bien establecido la Corte, dichos actos legislativos no pueden ser tramitados en sesiones extraordinarias (Concepto Sala de Consulta y Servivio Civil, 22 de junio de 2010).

Además, cabe reiterar que al tenor literal del artículo 149 de la Carta Política, todo lo actuado respecto del acto legislativo de reforma a la justicia que se llevó a cabo en las sesiones convocadas por el gobierno, carece de validez, ya que este reza de la siguiente manera: 
Toda reunión de miembros del Congreso que, con el propósito de ejercer funciones propias de la rama legislativa del poder público, se efectúe fuera de las condiciones constitucionales, carecerá de validez; a los actos que realice no podrá dárseles efecto alguno, y quienes participen en las deliberaciones, serán sancionados conforme a las leyes (Constitución Políticca de Colombia, Art. 149).

Con base en todo lo desarrollado anteriormente, es inevitable la siguiente pregunta: ¿Adquirió validez el acto legislativo de reforma a la justicia? Para dar respuesta a esta pregunta, se hace obligatorio y necesario recurrir a los requisitos de procedimiento que tienen los actos legislativos para su aprobación. Como lo hemos analizado anteriormente, uno de los principales requisitos es que el trámite se realice en dos períodos ordinarios consecutivos, que reciba aprobación por la mayoría de los asistentes, luego será publicado por el gobierno, esto en cuanto al primer período ordinario, en el segundo, solo podrán debatirse iniciativas presentadas en el primero, y requerirá el voto de la mayoría de los miembros de cada Cámara, para su aprobación. Esto para un total de 8 debates. La Corte Constitucional ha establecido una lista de los requisitos de aprobación de los actos legislativos:

1. En materia de iniciativa legislativa, pueden provenir del Gobierno, de los miembros del Congreso en número no inferior a 10, del veinte por ciento de los concejales o de los diputados, y de los ciudadanos en un número equivalente al menos al cinco por ciento del censo electoral vigente (C.P. Art. 375).

2. El proyecto debe publicarse en la Gaceta del Congreso antes de darle curso en la Comisión respectiva (C.P. artículo 157-1 y Ley 5 de 1992. Art. 144).

3. El proyecto debe tener informe de ponencia en la respectiva Comisión encargada de tramitarlo, y a él tendrá que dársele el curso correspondiente (C.P. Art. 160).

4. El proyecto deberá aprobarse en dos períodos ordinarios y consecutivos, de la siguiente manera: en la primera legislatura o período ordinario por la mayoría de los asistentes y en la segunda legislatura o período ordinario por la mayoría de los miembros de cada Cámara (C.P. Art. 375).

5. Aprobado el proyecto en el primer período, el Gobierno deberá publicarlo (C.P. Art. 375).

6. Durante el segundo período ordinario solamente pueden debatirse iniciativas presentadas en el primero (C.P. Art. 375 y Ley 5a de 1992 Art. 226).

7. Entre el primero y segundo debate deberá mediar un lapso no inferior a ocho (8) días, y entre la aprobación del proyecto en una de las Cámaras y la iniciación del debate en la otra, deberán transcurrir por lo menos quince días (C.P. Art. 160). Del mismo modo, deberá cumplirse con el requisito de anuncio previo de la votación en cada uno de los debates (C.P. Art. 160).

8. Durante el segundo debate cada Cámara podrá introducir al proyecto las modificaciones, adiciones y supresiones que juzgue necesarias (C.P. Art. 160 y Ley $5^{\text {a }}$ Art. 226). 
9. En el informe para la plenaria en segundo debate, el ponente deberá consignar la totalidad de las propuestas que fueron consideradas por la comisión y las razones que determinaron su rechazo (C.P. Art. 160).

10. Cuando surjan discrepancias entre las Cámaras respecto del proyecto, ambas integrarán comisiones de conciliación que procurarán conciliar los textos, y en caso de no ser posible, definirlo por mayoría (C.P. Art. 161).

11. El título del acto legislativo deberá corresponder exactamente a su contenido, y a su texto precederá esta fórmula: "El Congreso de Colombia, DECRETA:" (C.P. Art. 169) (Sentencia C-1040, 2005).

De esta manera vemos que el Acto legislativo que reformaba artículos de la Constitución en cuanto a la administración de justicia, cumplió con todos los requisitos, lo que permite concluir, que sí llegó a adquirir validez, pese a que no fue publicado por el presidente, ya que esto no condiciona su nacimiento al mundo jurídico, puesto que la publicación es una condición de eficacia y de oponibilidad, y así lo ha establecido la misma Corte Constitucional, como en el caso de la Sentencia C-025/12 (M.P. Mauricio González Cuervo):

La promulgación es un paso posterior al momento de la existencia de la ley, que guarda relación directa con su eficacia y oponibilidad: la obligatoriedad de las normas parte del conocimiento de estas por los ciudadanos llamados a cumplirlas, no pudiendo exigírseles el deber de su observación en tanto ignoren su existencia. La publicación de la ley es condición necesaria para su obligatoriedad y oponibilidad, sin que la promulgación de esta afecte la validez ni la existencia de la misma (2012).

El Consejo de Estado, de igual forma reitera que la publicación no es una condición de validez del acto, y lo sostiene así cuando en su sentencia plasma que:

La promulgación no forma parte del proceso de formación de la ley. Se trata de una actuación independiente y posterior que realiza el presidente de la república, una vez que el Congreso ha completado el proceso de formación, y que se encamina a garantizar su oponibilidad y eficacia, mediante su publicidad, fundamento de la aplicabilidad y acatamiento del ordenamiento jurídico (Sentencia 110010324000201200220, 2014).

Con lo anterior, se llega a la conclusión de que la Corte Constitucional sí debió pronunciarse de fondo sobre el Acto Legislativo de Reforma a la Justicia, ya que si bien el artículo 379 de la Carta Política en su inciso segundo establece que "La acción pública contra estos actos solo procede dentro del año siguiente a su promulgación, con observancia de lo dispuesto en el artículo 241 numeral 20" (Constitución Política de Colombia, Art. 379), también el mismo texto constitucional, cuando crea la Corte Constitucional, como lo dice su artículo 241, "le confía la guarda de la integridad y supremacía de la Constitución”, con esta competencia, y fin para el que fue creado este alto tribunal, se puede afirmar que sí debió pronunciarse la Corte Constitucional respecto de dicho acto legislativo. 
Queda en claro que el acto legislativo cobró validez, y que si no alcanzó a cumplir el requisito de la promulgación, para poder ser sometido al control de constitucionalidad en los términos que lo establece el artículo 379, fue por la objeción realizada por parte del presidente de la república, la cual, durante todo el artículo, y la Sentencia del 16 de septiembre de 2014 del Consejo de Estado, queda en claro que no procedía, ya que el presidente no cuenta con dicha competencia, como se ha venido argumentado. Entonces, fue un factor externo, además, contrario a la Constitución, el que impidió cumplir con los requisitos establecidos para llevar a cabo el control correspondiente a la Corte Constitucional; sin embargo, el acto legislativo, que ya contaba con plena validez, era contrario a la Carta Política, aunque más contrario aun, el procedimiento de objeción por parte del ejecutivo, y el de convocar al legislativo a sesiones extraordinarias para conocer de dichas objeciones, en últimas, sobre el acto legislativo en general, lo que también está prohibido en la Constitución, como se expuso anteriormente, cuando se establece que dichos trámites se deben cumplir en dos períodos ordinarios consecutivos, y no se admiten las sesiones extraordinarias.

Frente a este panorama de transgresión a la Constitución Política, tanto por parte del ejecutivo, como del legislativo, se hacía necesario el pronunciamiento de la Corte Constitucional como máxima guardadora de la Constitución y su integridad, a sabiendas de que este Tribunal contaba con los mecanismos necesarios para dicho control, en especial, el Test de Sustitución de la Constitución, ya que como lo enuncia el Consejo de Estado en la sentencia en cuestión, aun cuando

'Cualquier artículo de la Constitución puede ser reformado', no es válido sustituir la Carta so pretexto de reformarla, porque, en tal supuesto, se desnaturalizaría el poder de reformar la Constitución y se 'excedería la competencia del titular de ese poder', y estimó la Corte Constitucional que ello es así, pese a que el Constituyente Primario no estableció cláusulas pétreas, de donde se desprende que existe diferencia entre el carácter insustituible de la Constitución y la intangibilidad (Sentencia 110010324000201200220, 2014).

Debe entenderse la sustitución de la Constitución, en los términos de la Corte Constitucional:

El fenómeno jurídico de la sustitución de la Constitución se presenta cuando un elemento definitorio de la esencia de la Constitución de 1991, en lugar de ser modificado, es reemplazado por uno opuesto o integralmente diferente. Así, después de la sustitución de la Carta, como es imposible reconocerla en su identidad básica, no cabe afirmar que la Constitución reformada sigue siendo la Carta de 1991. Al Congreso de la República le está vedado sustituir la Constitución, en forma total o parcial, permanente o transitoria. Por supuesto, le está prohibido reemplazar la Constitución de 1991 por una completamente nueva y diferente. Pero tampoco puede sustituir la Carta mediante un cambio parcial de tal magnitud que haga imposible, de manera permanente o transitoria, reconocer en la Constitución los elementos esenciales definitorios de su identidad originaria, lo cual no obsta para que el Congreso efectúe 
reformas importantes para adaptar la Carta a la evolución de la sociedad y responder a las expectativas de los ciudadanos (Sentencia C-1040, 2005).

Para Segundo Linares Doctrina es competencia del poder judicial, en el caso colombiano, la Corte Constitucional, conoce y declara la inconstitucionalidad cuando haya sustitución de esta:

Una reforma de la Constitución será inconstitucional, y el poder judicial tiene competencia para declararlo así, en el respectivo caso que se someta a su decisión si ha sido sancionada en violación del procedimiento, condiciones o prohibiciones establecidas por el texto constitucional vigente, así como también si contradice, o sea, traiciona los principios o bases permanentes, es decir, el alma o espíritu de la Constitución (Linares, 1998).

También el Consejo de Estado, en su sentencia en la que declara la nulidad por inconstitucionalidad del Decreto 1351 de 2012, establece que:

Finalmente, conviene destacar que, de acuerdo con la jurisprudencia, el reemplazo de un elemento definitorio por otro opuesto o integralmente diferente, torna imposible la armonización de la pretendida reforma 'con el resto de normas constitucionales que no fueron modificadas por ella y que reflejan aspectos claves de lo insustituible', asunto que, como todos los comentados, le corresponde comprobar a la Corte Constitucional en ejercicio del control a ella asignado, cuya integralidad constitucionalmente exigida, le obliga a evaluar, en cada evento, la competencia del órgano reformador y determinar 'si las nuevas instituciones resultan de tal modo incompatibles con la Constitución anterior que unas y otras no pueden coexistir en el tiempo y en el espacio' (Sentencia 110010324000201200220, 2014).

Con todo lo anterior, se sobreentiende, que lo actuado por el Congreso de la República, y el presidente de la república, sustituye la Constitución, ya que genera nuevas competencias para el ejecutivo, como el de objetar actos legislativos, y en la rama legislativa, el de tramitar actos legislativos, fuera de los términos constitucionales, en sesiones extraordinarias, y que era entonces, necesario un fallo de la Corte Constitucional, pronunciándose de fondo sobre dicho atentado contra la integridad y supremacía de la Constitución Política de Colombia.

Para terminar, se concluye que la objeción presidencial a actos legislativos es improcedente en Colombia, ya que desde la misma constitución en su artículo 375 se limita la función del ejecutivo únicamente a la publicación de dicha reforma, y aun cuando este argumentase tal objeción en la inconstitucionalidad de la reforma o inconveniencia, es inválido el argumento, ya que la entidad competente para decidir la inconstitucionalidad de los actos reformatorios de la Constitución es la Corte Constitucional, tal y como lo establece el artículo 241 en sus numerales 1 y 2 .

1. Decidir sobre las demandas de inconstitucionalidad que promuevan los ciudadanos contra los actos reformatorios de la Constitución, cualquiera que sea su origen, sólo por vicios de procedimiento en su formación. 2. Decidir, 
con anterioridad al pronunciamiento popular, sobre la constitucionalidad de la convocatoria a un referendo o a una Asamblea Constituyente para reformar la Constitución, sólo por vicios de procedimiento en su formación (Constitución Política de Colombia, Art. 241).

Además, la Corte Constitucional al respecto se ha pronunciado en varias ocasiones, en la Sentencia C-543 de 1998 estableció que el acto legislativo no requiere de sanción presidencial, ya que el poder constituyente no se puede subordinar a los poderes constituidos. También en la Sentencia C-208 de 2005 se aclara que la objeción presidencial procede frente a los proyectos de ley, no a los de reforma constitucional como el acto legislativo, ya que este para su vigencia no requiere la sanción ni está autorizado el presidente constitucionalmente para objetarla y, por último, la Sentencia C-178 de 2007, donde se recalca la función del presidente de la república de publicar la reforma, mas no de sancionarla u objetarla, ya que el Congreso goza de voluntad autónoma y no requiere la concurrencia de la voluntad del ejecutivo. Con lo anterior, se configura una línea jurisprudencial que aclara la improcedencia de las objeciones del ejecutivo a los actos de reforma constitucional, y siendo la Corte Constitucional la guardiana de la integridad y supremacía de la Constitución, como lo establece el artículo 241 constitucional, debe acatarse lo que esta corporación ha dicho al respecto y, por tanto, dichas objeciones se deben tener como improcedentes y no deben tener validez, ya que con esta figura se atenta contra la Constitución y contra el poder constituyente.

También, se llega a la conclusión de que, en el ordenamiento constitucional colombiano ya se había contemplado antes la objeción presidencial a actos legislativos, al punto que dos de nuestras constituciones anteriores le confería dicha facultad al ejecutivo, siendo esta la Constitución Granadina de 1843 y la Constitución Política de Colombia de 1886, y que se tuvo una objeción a actos legislativos, siendo este el caso del Acto Legislativo número 3 de 1910.

En el ejercicio de análisis de referente con otras constituciones de América Latina, se encuentran países donde está permitida la objeción presidencial a las reformas constitucionales como el acto legislativo, siendo este el caso de la Constitución de Chile y Costa Rica, donde expresamente el mismo texto constitucional le otorga dicha facultad al ejecutivo. También la Constitución de Ecuador de 1998, permitía de manera clara, la objeción presidencial a las reformas del texto constitucional, esta Constitución ya no está vigente, Ecuador actualmente se rige por la Constitución de 2008, pero sí es importante resaltar que, en su momento en este país, en su historia constitucional era permitida esta figura. Por otra parte, es mayor el número de países donde es improcedente esta objeción, también se tienen constituciones como la de Perú, Venezuela, Nicaragua, República Dominicana, Panamá y Bolivia, las cuales de manera clara y taxativa prohíben la objeción presidencial a las reformas constitucionales, dentro de las cuales se encuentra los actos legislativos, esto con el fin de salvaguardar la voluntad del constituyente primario y del secundario, garantizando un ejercicio de reforma más conveniente al Estado, a sus ciudadanos, y 
apartando la voluntad política de un mandatario de turno de una decisión de tan gran magnitud e importancia al mundo jurídico, como lo es una reforma constitucional, todo esto para concluir que es improcedente y abiertamente inconveniente y peligroso para el constitucionalismo de un país, el hecho de que un presidente vete las decisiones reformatorias de los textos constitucionales.

Con todo lo anterior, se determina que así como hay constituciones que permiten las objeciones presidenciales a los actos legislativos como reforma constitucional, también la mayoría de las constituciones de América Latina lo prohíben, limitan en gran proporción la presencia del ejecutivo en las reformas a sus textos fundamentales para evitar que se vea sujeta la voluntad del Congreso de la República o en determinados casos asambleas nacionales a la voluntad y decisión de dicho poder, en cabeza del presidente.

Así, se da por finalizado el presente artículo, donde se analizó el proceso que surtió el Acto Legislativo de Reforma a la Justicia, las objeciones presidenciales, la convocatoria a sesiones extraordinarias al Congreso de la República para conocer dichas objeciones, y la Sentencia del 16 de septiembre del Consejo de Estado, que declara la Nulidad por Inconstitucionalidad del Decreto 1351 de 2012 que convocaba a dichas sesiones extraordinarias, además, sentencia en la cual se analiza de gran manera la improcedencia de dichas objeciones y de tal competencia presidencial inexistente en nuestro ordenamiento jurídico, y por último, donde se concluyó que la Corte Constitucional sí debió pronunciarse de fondo sobre el gran problema constitucional que ocasiono dicho Acto Legislativo.

\section{REFERENCIAS}

Argüello-Rueda, J. D. (2014). ¿Es procedente la objeción presidencial a actos legislativos en Colombia? DISSERTUM, 27.

Böckenförde, E. W., y de Agapito, R. (2000). Estudios sobre el Estado de derecho y la democracia (Vol. 200). Madrid: Trotta.

Concepto Sala de Consulta y Servivio Civil (22 de junio de 2010).

Constitución de la República de Venezuela. (Art. 175).

Constitucion Granadina de 1843. (Art. 73).

Constitucion Política de Colombia. (Art. 113).

Constitucion Politica de Colombia. (Art. 237, \# 2).

Constitución Política de Colombia. (Art. 241).

Constitución Política de Colombia. (Art. 375).

Constitución Política de Colombia. (Art. 379).

Constitución Política de Colombia de 1886. (Art. 151, \# 4).

Constitución Política de la República de Costa Rica. (Art. 195).

Constitución Política de la República de Panamá. (Arts. 313, 314).

Constitución Política de Perú. (Art. 206). 
Constitución Políticca de Colombia (Art. 149).

Decreto 1351 de 2012. (s.f.).

Ley 5 de 1992. (Art. 227).

Linares, S. (1998). Tratado de Interpretacion constitucional. Buenos Aires: Artes Gráficas Candil.

Sentencia 110010324000201200220, 11001032400020120022000 (Consejo de Estado 16 de 09 de 2014).

Sentencia C-025 (Corte Constitucional 2012).

Sentencia C-1040 (Corte Constitucional 2005).

Sentencia C-251 (Corte Constitucional 11 de 04 de 2002). 